\title{
THE DIFFERENCES SCORE OF POSITIVE AND NEGATIVE SYNDROME SCALE NEGATIVE SCALE BETWEEN SCHIZOPHRENIC PATIENTS THAT RECEIVED RISPERIDONE AND RISPERIDONE WITH FLUOXETINE
}

\author{
RITHA M SEMBIRING*, MUSTAFA M AMIN, ELMEIDA EFFENDY \\ Department of Psychiatry, Medical Faculty, Universitas Sumatera Utara, Medan, Indonesia. Email: ritha94@yahoo.com \\ Received: 15 October 2018, Revised: 06 February 2018 and Accepted: 14 February 2018
}

\begin{abstract}
Objective: Negative symptoms are relatively common with a recent study finding that nearly $58 \%$ of outpatients had at least one negative symptom, negative symptoms are better predictors of functioning than positive symptom. Antidepressants have been a natural and common choice for the treatment of negative symptoms considering the conceptual proximity of their mode of action and the etiological hypotheses involving related neurotransmitters. This study examined differences negative symptoms scale score between patient that received only risperidone and risperidone with fluoxetine.

Method: The sample consist of 44 patients with a diagnosis of schizophrenia according to ICD-10 (International Statistical Classification of Diseases), male, age ranged was between 30 and 50 years, signed informed consent before entering into study which had been conducted at the Prof. Dr. M Ildrem Mental Health Hospital Medan Sumatera Utara Indonesia. The study was designed for 4 weeks, open-label, divided into two groups of 22 each, (1) receiving $4 \mathrm{mg}$ /day risperidone with $20 \mathrm{mg}$ /day fluoxetine and (2) receiving only $4 \mathrm{mg} /$ day risperidone. Negative symptoms were assessed using positive and negative syndrome scale (PANSS).
\end{abstract}

Results: The primary finding of the trial was a significant reduction in score ofnegativescale in patients receiving risperidone with fluoxetinecompared to patients receiving only risperidone at the end of 4 weeks. All the subscales of PANSS negative symptoms scale demonstrated significant improvement.

Conclusions: In patients with schizophrenia, treating negative symptoms with adjunctive to fluoxetine appears to carry the benefit of improving negative symptoms.

Keywords: Negative symptom, Risperidone, Fluoxetine, Positive and negative syndrome scale.

(c) 2018 The Authors. Published by Innovare Academic Sciences Pvt Ltd. This is an open access article under the CC BY license (http://creativecommons. org/licenses/by/4. 0/) DOI: http://dx.doi.org/10.22159/ajpcr.2018.v11s1.26563

\section{INTRODUCTION}

Schizophrenia, which afflicts approximately $1 \%$ of the population, usually begins before age 25 , persists throughout life, and affects people of all social classes [1].

Patients with schizophrenia struggle with many functional impairments, including performance of independent living skills, social functioning, and occupational educational performance and attainment [2].

Schizophrenia's symptoms are classified into three groups: Positive symptoms, such as hallucinations and delusions; negative symptoms, such as apathy and social withdrawal; and cognitive symptoms, such as poor executive functioning and working memory [3].

Research suggests that the negative symptoms of schizophrenia, including problems with motivation; social withdrawal; and diminished affective responsiveness, speech, and movement, contribute more to poor functional outcomes, and quality of life for individuals with schizophrenia than do positive symptoms [2].

Recent attention has focused on the development of pharmacological agents that have a specific activity in treating negative symptoms that can be added to an antipsychotic medication [4].

The heterogeneous nature of schizophrenia symptoms complicates the process of determining relative risks and benefits of using antidepressants in schizophrenia management [5].

Many reports are currently available involving trials of antidepressants in treating the negative symptoms of schizophrenia [6].
Several classes of antidepressants have been studied as potential treatments for negative symptoms [7]. A number of studies have demonstrated that adding SSRI antidepressants to antipsychotics can improve negative symptoms resistant to antipsychotic alone [8].

The response is in negative symptoms primary to the illness, requires a serotonergic mechanism, and can be detected within 2 weeks of starting augmentation. Several SSRI antidepressants inhibit cytochrome P-450 enzymes, mainly CYP1A2 and CYP2D6 isozymes,

which are metabolizers of antipsychotic drugs. Adding anSSRI antidepressant drug often results in an increase in plasma levels of the antipsychotic, which could underlie the superior efficiency of the augmentation treatments [8].

Several characteristics of the SSRI antidepressant - antipsychotic combination makes it a useful paradigm for studying therapeutically effective synergistic drug interactions in schizophrenia. First, the clinical effect is specific for a particular subset of clinical symptoms (negative symptoms), one that constitutes a core dimension of the illness, with a response detectable within 2 weeks. Second, it is dependent on the serotonergic action of the SSRI but not due to a general antidepressant effect. Third, the molecular mechanisms cannot be explained by the known actions of the individual drugs [8].

A pilot study showed that fluoxetine added to neuroleptics improves both positive and negative symptoms in treatment-resistant schizophrenic patients [9]. Several clinical reports have dealt with a combination of risperidone and fluoxetine [10].

In this study, we examined differences negative symptoms scale score between patient that received only risperidone and risperidone with fluoxetine. 
Table 1: Baseline characteristics of sample

\begin{tabular}{|c|c|c|c|}
\hline Variable & Risperidone group & Risperidone+fluoxetine group & $\mathbf{p}$ \\
\hline \multicolumn{4}{|l|}{ Total N } \\
\hline \multicolumn{4}{|l|}{ Age (years) } \\
\hline Mean \pm SD & $34.41 \pm 3.59$ & $34.27 \pm 3.35$ & $0.89 *$ \\
\hline \multicolumn{4}{|l|}{ Ethnic, n (\%) } \\
\hline Batak & $10(45.5)$ & $11(50.0)$ & $0.76^{* *}$ \\
\hline Non batak & $12(54.5)$ & $11(50.0)$ & \\
\hline \multicolumn{4}{|l|}{ Level of education, $\mathrm{n}(\%)$} \\
\hline $\begin{array}{l}\text { Primary-junior high } \\
\text { school }\end{array}$ & $11(50.0)$ & $10(45.5)$ & $0.76^{* *}$ \\
\hline Senior high school-college & $11(50.0)$ & $12(54.5)$ & \\
\hline \multicolumn{4}{|l|}{ Duration of illness } \\
\hline Mean \pm SD & $9.23 \pm 2.79$ & $9.59 \pm 3.34$ & $0.91^{* * *}$ \\
\hline \multicolumn{4}{|l|}{ Body mass index } \\
\hline Mean \pm SD & $22.28 \pm 2.05$ & $21.67 \pm 1.93$ & $0.31 *$ \\
\hline \multicolumn{4}{|l|}{ PANSS negative } \\
\hline Mean \pm SD & $31.36 \pm 1.62$ & $31.64 \pm 1.96$ & $0.61^{*}$ \\
\hline
\end{tabular}

*Independent sample t-test, $* *$ Chi-square test, ${ }^{* *} *$ Mann-Whitney test

Table 2: Differences in negative symptoms scale score at the time of last visit (after 4 weeks)

\begin{tabular}{llll}
\hline Patient group & $\mathbf{n}$ & Mean (SD) & p \\
\hline Risperidone group & 22 & $28.59(1.68)$ & $0.001^{*}$ \\
Risperidone+fluoxetine group & 22 & 24.59 & $(2.32)$ \\
\hline${ }^{*}$ Independent sample t-test & & &
\end{tabular}

We hypothesize effect of adjective fluoxetine to risperidone treatment on negative symptoms partly reflect a significant reduction in negative symptom scale.

\section{METHODS}

\section{Study population}

Participants were recruited from Prof.Dr. M Ildrem Mental Health Hospital Medan Sumatera Utara Indonesia, with a diagnosis of schizophrenia according to ICD-10 (International Statistical Classification of Diseases) predominant negative symptoms with negative symptom score each item $\geq 4$, age ranged was between 30 and 50 years, male, outpatient setting, were on a stable dose of risperidone for at least 4 weeks, and a written informed consent was obtained from participants or their legally authorized representatives before the initiation of study procedures.

Potential participants were excluded if they met clinical diagnosis of chronic medical illness had active substance abuse or dependence which (except caffeine and nicotine)

\section{Study treatments}

The study was designed for 4 weeks, open-label, divided into two groups of 22 each, (1) receiving $4 \mathrm{mg}$ /day risperidone with $20 \mathrm{mg} /$ day fluoxetine and (2) receiving only $4 \mathrm{mg} /$ day risperidone. Subjects were instructed to take their study medication at the same time each day.

\section{Assessments}

Screening evaluations included the Mini-Structured Clinical Interview for DSM-IV axis 1 disorders. After informed consent was signed, we obtained psychiatric and medical history, documented vital signs and physical examination. Negative symptoms were assessed using the positive and negative syndrome scale (PANSS). Negative symptoms assessments were done during study visits at weeks 1 and $4^{\text {th }}$

\section{RESULTS}

There were 22 patients in group that received risperidone only and 22 in group that received risperidone with fluoxetine (Table 1). The groups did not differ at baseline in demographic characteristics, body mass index, and PANSS negative symptoms scale. There were no significant differences between the two groups.
We compare PANSS negative score at the last available visit (Table 2). The patients in the risperidone with fluoxetine group had significantly lower scores on the PANSS negative symptoms scale. The results, described in Table 2, show that the PANSS negative component (composed of items measuring blunted affect, emotional withdrawal, poor rapport, passive, apathetic, social withdrawal, lack of spontaneity, and motor retardation) was significantly lower (i.e., significantly improved) in the risperidone with fluoxetine group.

\section{DISCUSSION}

To study how augmenting antipsychotic medications with anti-depressants impacts negative symptoms of schizophrenia, we analyzed data from a clinical trial comparing patients treated with risperidone with fluoxetine to those treated with risperidone alone. To the best of our knowledge, this is the first study in middle-aged with schizophrenia assessing effects of adding SSRIs to antipsychotic medications on schizophrenia symptoms in Prof. Dr M. Ildrem Mental Health Hospital Medan Sumatera Utara.

We noted that fluoxetine augmentation appears to improve negative symptoms that may impair social functioning - rapport, flow of conversation, spontaneity, apathy, and social withdrawal. It also appears to improve motor retardation. Since negative symptoms have been associated with worse functioning and quality of life, improving this important.

The dimension of schizophrenia with antidepressants may produce a cascading chain of benefits resulting in improved functioning and quality of life. It is noteworthy that these benefits were obtained without simultaneous worsening of positive symptoms. Our finding that fluoxetine augmentation did not worsen positive symptoms is consistent with recent reports. Fluoxetine $20 \mathrm{mg} /$ day has been reported to significantly increase steady-state serum risperidone concentrations [11].

\section{CONCLUSION}

In patients with schizophrenia, treating negative symptoms with adjunctive to fluoxetine appears to carry the benefit of improving negative symptoms.

\section{ACKNOWLEDGMENT}

None.

\section{CONFLICTS OF INTERESTS}

None. 


\section{REFERENCES}

1. Sadock BJ, Sadock VA. Kaplan and Sadock's Concise Textbook of Clinical Psychiatry. $2^{\text {nd }}$ ed. Philadelphia, PA: Lippincot Williams \& Wilkins Publisher; 2004.

2. Velligan DI, Alphs LD. Negative symptoms in schizophrenia: The importancce of identification and treatment. Psychiatr Times 2013;25:24-6.

3. Kingwell K. Schizophrenia drug gets negative result for negative symptoms. Nat Rev Drug Discov 2014;13:244-5.

4. Arango C, Garibaldi G, Marder SR. Pharmacological approaches to treating negative symptoms: A review of clinical trials. Schizophr Res 2013;150:346-52.

5. Vahia IV, Lanouette NM, Golshan S, Fellows I, Mohamed S, Kasckow JW, et al. Adding antidepressants to antipsychotics for treatment of subsyndromal depressive symptoms in schizophrenia: Impact on positive and negative symptoms. Indian J Psychiatry 2013;55:144-8.
6. Sp S, Sing V, Kar N, Chan K. Efficacy of antidepressants in treating the negative symptoms of chronic schizophrenia: Meta-analysis. BJPsych 2010;197:174-9.

7. Davis MC, Horan WP, Marder SR. Psychopharmacology of the negative symptoms: Current status and prospects for progress. Eur Neuropsychopharmachol 2014;24:788-99.

8. Silver H, Chertkow Y, Weinreb O, Danovich L, Youdin M Multifunctional pharmacotherapy: What can we learn from study of selective serotonin reuptake inhibitor augmentation of antipsychotics in negative-symptom schizophrenia? Neurotherapeutics 2009;6:86-93.

9. Goff DC, Brotman AW, Waites M, McCormick S. Trial of fluoxetine added to neuroleptics for treatment-resistant schizophrenic patients. Am J Psychiatry 1990;147:492-4

10. Bondolfi G, Eap CB, Bertschy G, Zullino D, Vermeulen A, Baumann P. The effect of fluoxetine on the pharmacokinetics and safety of risperidone in psychotic patients. Pharmacopsychiatry 2002;35:50-6.

11. Kennedy WK, Jann MW, Kutscher EC. Clinically significant drug interactions with atypical antipsychotics. CNS Drugs 2013;27:1021-48. 